\title{
Breaking out of the bubble
}

\author{
The biotech community has made remarkable progress over the past 20 years. Now it needs to break out of its bubble.
}

ince this journal was relaunched 20 years ago, biotech has brought hundreds of innovative medical, agricultural and industrial products to market. It has changed the lives of millions. It has made the livelihoods of millions. It is also no longer just recombinant DNA technology, but a broader set of principles and tools for engineering living systems. We can synthesize genes and proteins. We can assemble gene circuits. We can edit genomes. And we can print molecules, cells and even simple tissues. With such powerful technology, biotech should reach more and more corners of human life in the coming years. But this will happen only if society remains in step with technological advancement. And that requires the biotech community to break out of its bubble.

Over the past two decades, Nature Biotechnology has published some of the technologies behind the many recombinant proteins and monoclonal antibodies that have turned biotech into a multibillion dollar business. We have presented some of the advances behind bioengineered corn, soybean, canola, sugar beet and cotton varieties that have changed the face of agriculture. We have highlighted microbial engineering efforts that have led to greener, sustainable processes for producing fuels, chemicals and materials.

During that time, the wider world changed, too. In 1996, Nature Biotechnology had no 'web presence'. Only geeks with 33.6-kb modems and a high tolerance for disconnection used the Internet. Google was 100 to the power 100; Amazon was two years old. There was no Wikipedia, no Facebook, no Twitter. News came on TV. Newspapers through the letterbox. This journal was read on paper. China and India were far-off, poor places. The European Union had 15 member countries, none from Eastern Europe. New York had twin towers. The world was more introspective, less global and much less informed.

Reality has changed but the public image of biotech has hardly shifted. Many in the public may have heard of the Human Genome Project. Others of GMOs. Some may even have heard of Synthia, the first synthetic organism rebooted from an artificial chromosome. But few outside the biotech inner circle really appreciate the radical changes that have taken, and continue to take, place.

So many things are happening so rapidly, it's difficult for anyone to keep up. DNA sequencing power has gone from one human genome in 13 years to one every few hours. We can now 'write' sequence; we have engineered enzymes (zinc finger nucleases, TALENs and CRISPRCas9) that can edit our code; DNA synthesis costs have dropped 1,000-fold since 1996 to one cent per base; bits can be turned into atoms without human intervention through automated oligo synthesizers; three-dimensional scanners can turn living systems into digital information and bioprinters reproduce rudimentary representations of them; sequencing platforms, mass spectrometry and mass cytometry instruments can measure nucleic acids, proteins, metabolites, epigenetic and post-translation modifications and metabolites on a genome-wide level all the way down to single cells; new imaging methods are revealing living systems in unprecedented clarity and detail.

The pace of change means that we need to redouble our efforts to communicate them to the public. We can no longer remain in our bubble, talking to one another. We must spend more time looking out of the bubble and listening.

By being inward looking, the biotech community has appeared tone deaf to criticisms of its business practices. There are good reasons why companies need to charge high premiums for innovative bioengineered products. But arguing about the importance of R\&D spending, attrition in drug development and the cost of clinical trials means little to ordinary people who are increasingly picking up the ticket for these drugs out of their own pockets.

Tackling the aloof image of biotech in the public eye means going beyond trite communication about healing ills, fueling the planet or feeding the world. We need to engage with the public about the social benefits - and costs - of new technologies that will impact everyday life. The worlds of research and clinic are converging. Smart technology, soft materials and stretchable electronics presage a time when data-collection devices will become more discreet and less invasive. Mobile devices and wearable sensors will present new possibilities to change our lives and behaviors. We will learn not only more about ourselves-our biology and that of our microbial flora-but also about the environment that we inhabit and care for.

We must recognize that our old model of communication will not work. Twenty years of passive, osmotic information flow from the biotech bubble to the outside world has done little to change public science literacy. Irrational fears about GMOs have not changed much since the 1990s. Transgenic animals remain recalcitrantly unpalatable as food. Deriving stem cells from human embryos remains as controversial as ever.

People have lives to lead, bread to win, families to raise, dreams to fulfill. They have little time to find out what biotech can do now or why they should care about it.

As the world of biotech moves from microbe manipulation to human biology, more needs to be done to debate the changes that may be coming. An informed dialog needs to be had about technological solutions that some may find morally discomforting, such as modifying the human germline, farming animals for humanized organs, engineering human enhancements and altering ecological niches for health objectives (e.g., transgenic mosquitoes against malaria or the Zika virus). Society needs to grapple with the privacy and security issues associated with wiring health and personal data into the web.

Public engagement is difficult. But one thing we can be sure of is that constructive dialog will not happen if biotech insiders remain within their bubble. We need to hear what people on the outside are thinking. 